\title{
THE INFLUENCE OF CORROSION ON RELIABILITY AND INSPECTION PROGRAM FOR FATIGUE-PRONE AIRFRAME STRUCTURES
}

\author{
M.S. Wahab, Yu.M. Paramonov
}

Riga Technical University, Aviation Institute, Riga,Latvia.E-mail: shujawahab@hotmail.com,rauprm@junik.lv Received 2104 2004, accepted 07102004

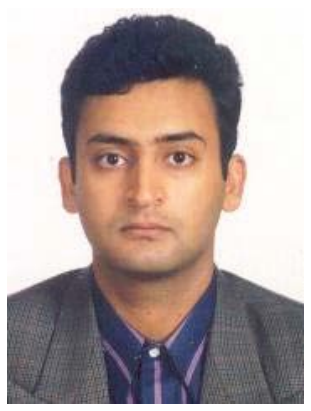

\author{
M. Shujauddin WAHAB, PhD Student \\ Date and place of birth: November 09, 1976 in Karachi (Pakistan) \\ Education: Master's degree, Aviation Institute, Riga Technical University, Latvia, 2004 \\ Conferences: International Conference "Reliability and Statistics in Transportation and Communication" \\ (RelStat'03), Riga, 16 -17 October 2003, Latvia. \\ The 44th International Scientific Conference Of Riga Technical University devoted to The Century of Aircraft; \\ section "Aviation Transport," 17-18 December 2003, Latvia. \\ Address: Aviation Institute, Riga Technical University, Lomonosova 1, LV-1019, Riga, Latvia, Tel.: +371 7089950.
}

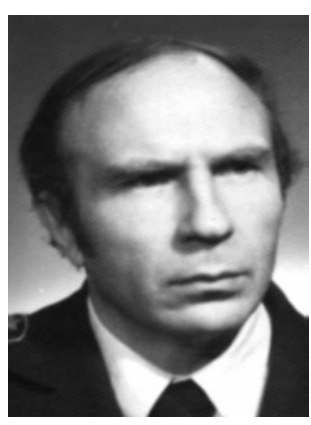

Yuri M. PARAMONOV, Prof Dr Habil Sc Ing.

Date and place of birth: March 28, 1938, Leningrad.

Education: Riga Aviation Engineering Military High School, Mechanical Engineering Diploma with golden Medal (1960). Riga Civil Aviation Eng. Institute, Doctor Sc. Eng. Degree (1965). Latvian Academy of Sciences, High Doctor Degree in Technical Cybernetics (1974). Riga Aviation University and Latvian Academy of Science, Doctor Habilitus Degree in Engineering (1993).

Fields of research: Reliability of technical systems; mathematical statistics; loads, structure and strength analysis of transport vehicle; information technology application (development of automated control systems).

Member of professional Societies: American Statistical Association, Research Board of Advisors of the American Biografical Institute, Participation in 15 international conferences;

Publications: 145, including 9 monographs and textbooks.

Honours, awords: Honoured Scientist of Latvian Soviet Socialist Republic (1983); order: Honour Decoration (1971); Medals: For Valiant Labour (1970), Labour Veteran (1985); Nomination as an International Man of the Year for $1997 / 98$ by the International Biografical Centre of Cambridge.

Present position: Professor of Aircraft Theory and Structure Department of Aviation Institute of Riga Technical University, Lomonosova street, 1,Riga, LV-1019, Latvia, +(371)-2255394, + (371) - 7089966.

Abstract. This paper is devoted to a discussion and solution of the following problems: Determination of mean value and variance of estimates of parameters of fatigue crack growth model for both the corroded and non-corroded types of specimens; Inspection modeling with the use of the Monte Carlo method for calculation of probability of fatigue failure as a function of inspection number; Determination of the number of inspections required for the limitation of fatigue failure probability; Comparison of required reliability for corroded and non-corroded cases. Special programs have been developed for necessary calculations. It was confirmed that the influence of corrosion has a great impact on the required number of inspections.

Key words: fatigue crack growth, corrosion medium, failure probability, inspection program and specified life.

\section{List of symbols and abbreviations}

\begin{tabular}{|c|c|}
\hline 1. $a(t)$ & $=$ Fatigue crack size at time $\mathrm{t}$; \\
\hline 2. a (0) & $\begin{array}{l}\text { =Equivalent beginning size of the } \\
\text { crack; }\end{array}$ \\
\hline$\Delta$ & $=$ Interval between inspections; \\
\hline $\mathrm{K}_{\mathrm{c}}$ & $\begin{array}{l}=\text { Critical value of stress intensity } \\
\text { factor; }\end{array}$ \\
\hline$t_{d}$ & $\begin{array}{l}=\text { Time when the fatigue crack is } \\
\text { detectable; }\end{array}$ \\
\hline $\mathrm{t}_{\mathrm{f}}$ & $\begin{array}{l}=\text { Time when there is a structural } \\
\text { failure; }\end{array}$ \\
\hline$P_{f}$ & $=$ Probability of failure; \\
\hline $\mathrm{m}, \ln \mathrm{Q}$ & $=$ Crack growth function parameters; \\
\hline$\mu$ & $\begin{array}{l}=\text { Depends on the material } \\
\text { characteristics; }\end{array}$ \\
\hline
\end{tabular}
10. $\mathrm{w}=\mathrm{Is}$ a probability that planned inspection will be made with required accuracy;
11. $\mathrm{n} \quad=$ Required number of inspections;
12. $\mathrm{Q} \quad=$ Parameter representing crack growth speed;
13. $\mathrm{C}_{\mathrm{d}}, \mathrm{C}_{\mathrm{f}}=$ Constants;
14. $\sigma_{\max }=$ Maximum stress in flight;
15. $t_{1} \quad=$ Choice of first interval;
16. $\mathrm{T}_{\mathrm{SL}}=$ Specified life of an aircraft;
17. $\theta_{0}\left(t_{f}\right)=$ Mean value of $\ln \left(t_{f}\right)$;
18. $\theta_{1}\left(\mathrm{t}_{\mathrm{f}}\right)=$ Standard Deviation of $\ln \left(\mathrm{t}_{\mathrm{f}}\right)$;
19. $t_{1}=$ The choice of first interval
20. MSD = Multiple site fatigue damage




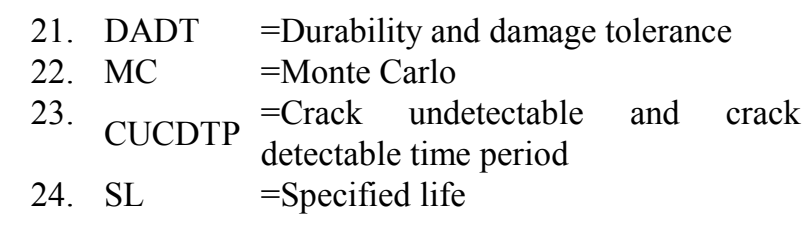

\section{Introduction}

Fatigue crack growth analysis in the presence of corrosion is an important subject, as shown in Fig 1, because it can degrade structural integrity and damage tolerance of fatigue critical structural components in aging aircrafts [3]. Multiple site fatigue damage (MSD) in a longitudinal skin splice has been recognized as a major airworthiness problem. It had a very significant influence on the Aloha B-737 incident in 1988.

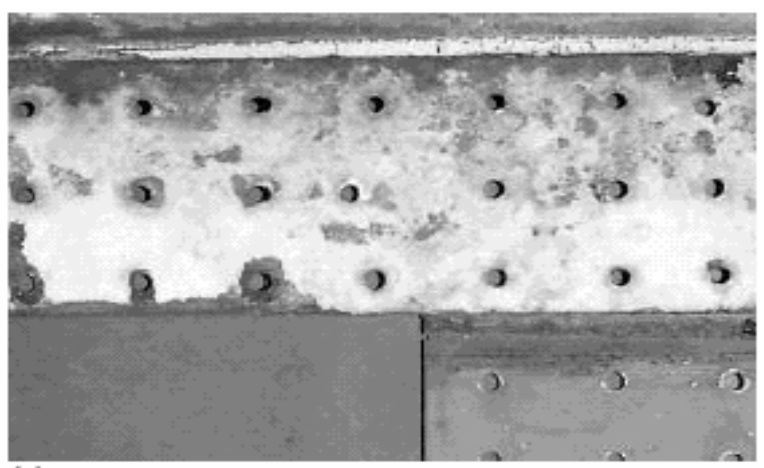

(a)

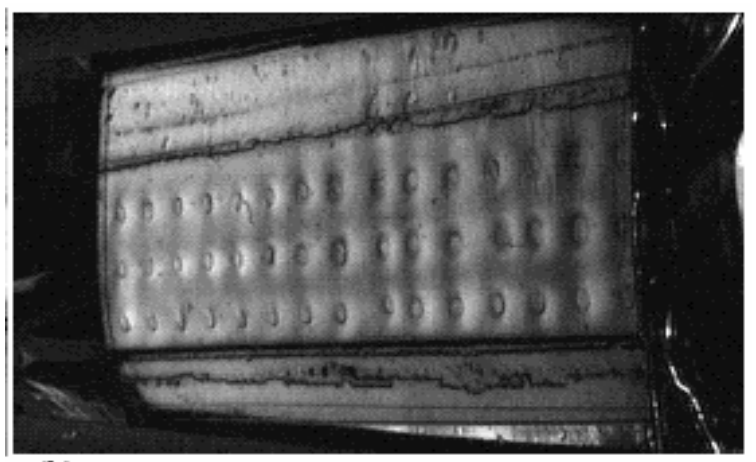

(b)

Fig 1. Illustration of a corroded longitudinal fuselage splice from a retired 727: (a) white corrosion product on faying surface, (b) corrosion pillowing detected by D Sight

For fleet management, it is important to know the effects of corrosion in normal service on the durability and damage tolerance (DADT) characteristics of the fuselage. The DADT characteristic of any structure are defined by the crack initiation and growth patterns, the critical crack scenarios that could develop, and the number of load cycles it takes for cracks to become detectable and then grow to a critical condition.

The crack development in a combined MSD and corrosion environment has characteristics that are quite different in form and more stochastic than those related to a single crack situation.

The probabilistic analysis methodologies should be as simple as possible while maintaining reasonable accuracy for predicting the failure probability of fatigue- critical components. The objective of this paper is to propose an accurate and cost-effective methodology for probabilistic analysis of lap splices that could be used in durability and damage tolerance assessments.

\section{Test program}

The MSD concept is illustrated by the generic lap splice version of the specimen clearly shown in Figure 2. A finite element model of the loop stress distribution in specimens is also shown. The concept is the use of bonded side straps to simulate the load transfer from cracked areas to surrounding structure that occurs on aircraft. The specimen shown is a $25.4 \mathrm{~cm}$ wide version designed to be representative of the longitudinal fuselage splices in some narrow body transport aircraft. The splice in the generic specimen comprises two sheets of $1.0 \mathrm{~mm}$ thick 2024-T3 Alclad is held by three rows of $4 \mathrm{~mm}$ diameter 20177-T4 rivets (MS20426AD5-5) without adhesive, paint or sealant. The rivet geometry results in a knife-edge countersink.

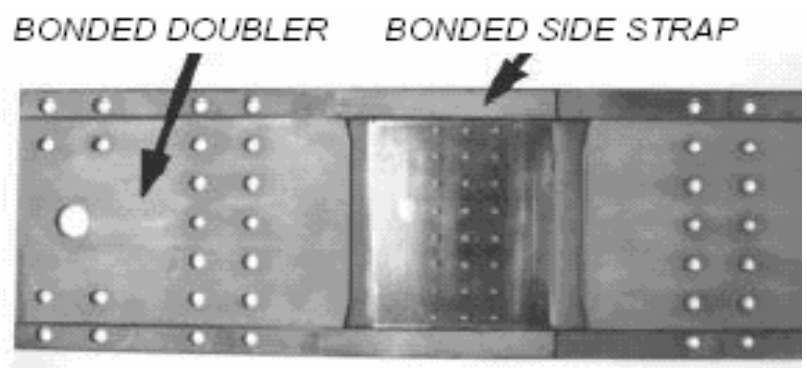

(a)

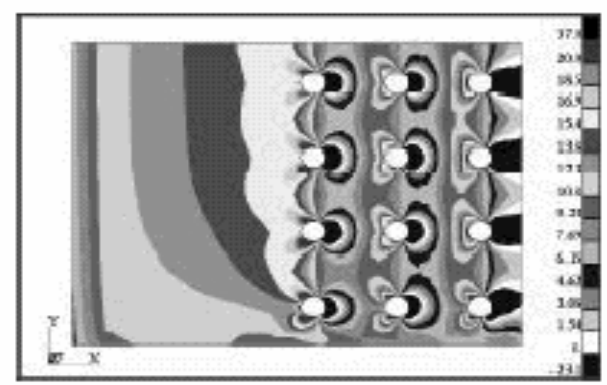

(b)

Fig 2. Illustration of MSD specimen (a) bonded doublers, (b) with a hoop stress distribution at faying surface by finite element prediction

The average cycle number for the final failure for the corroded specimens is 207640 cycles. As shown in Figure 3, the corrosion damage in this MSD specimen (average thickness loss of between $5 \%$ and 6\%) was compared with the damage in a section of splice from a Boeing 727 aircraft, shown in Figure 1, which was naturally corroded to a comparable level during 48.665 flights over 24 years. So one flight is approximately equivalent to 4.266 cycles. 


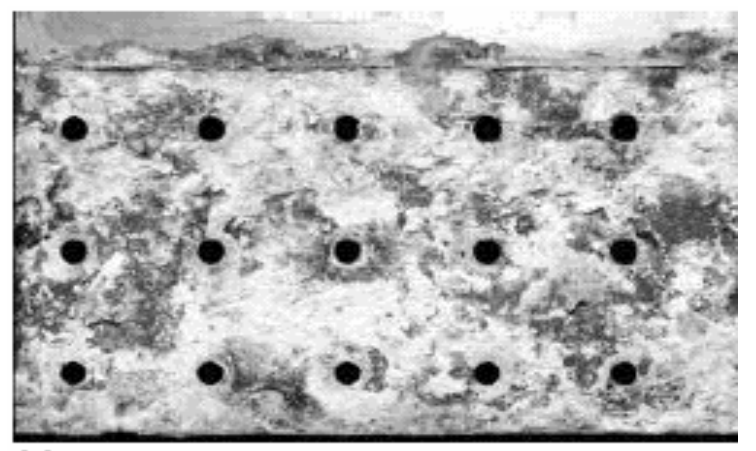

(a)

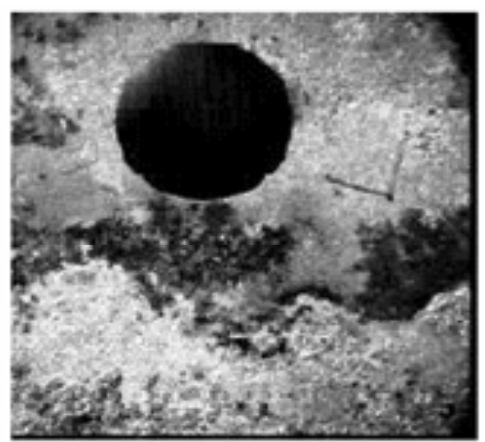

(b)

Fig 3. MSD specimen corroded to $5 \%$ to $6 \%$ average thickness loss: (a) countersunk sheet with corrosion product still in place,

(b) close-up near hole with corrosion product removed

The combination of corrosion and fatigue assumes that corrosion/fatigue interactions occurs only in the context of pre-existing corrosion and in a dry splice. This is a reasonable approximation for two reasons. First, teardown of aircraft splices and evidence indicates that substantial corrosion often exists without any associated fatigue cracking. Second, the highest in-service loads occur when any moisture in the splice is likely to be frozen.

There are altogether nine MSD specimens out of which five are non-corroded and four are relatively heavily corroded. They all are fatigue tested. These specimens are listed in Table 1 along with their respective fatigue life at visible crack detection, first link up, and final failure.
Table 1. Fatigue life of MSD Specimen

\begin{tabular}{|c|c|c|c|c|}
\hline \multicolumn{2}{|c|}{ Specimen \# } & \multicolumn{3}{|c|}{ Fatigue Life (Cycles) } \\
\hline & & $\begin{array}{c}1^{\text {st }} \\
\text { observed }\end{array}$ & $\begin{array}{c}1^{\text {st }} \\
\text { Linkup }\end{array}$ & $\begin{array}{l}\text { Final } \\
\text { failure }\end{array}$ \\
\hline \multirow{5}{*}{$\begin{array}{l}\text { Non- } \\
\text { corroded }\end{array}$} & Cgc-f38 & 387500 & 491711 & 501933 \\
\hline & Cgc-f46 & 314000 & 398908 & 403718 \\
\hline & Cgc-f51 & 304001 & 381378 & 392591 \\
\hline & Cgc-f60 & 290000 & 368650 & 378754 \\
\hline & Cgc-f61 & 368500 & 473397 & 481353 \\
\hline \multicolumn{4}{|c|}{ Average Final Failure } & 431670 \\
\hline \multirow{4}{*}{$\begin{array}{l}\text { Corroded } \\
\text { to } 5 \% \text { - } \\
6 \% \text { level }\end{array}$} & Cgc-cf34 & 160001 & & 222450 \\
\hline & Cgc-cf43 & 144000 & & 189074 \\
\hline & Cgc-cf45 & 104107 & & 177129 \\
\hline & Cgc-cf58 & 142000 & & 241909 \\
\hline \multicolumn{4}{|c|}{ Average Final Failure } & 207640 \\
\hline
\end{tabular}

\section{Failure characteristics}

A significant difference was noticed in the behavior of the MSD specimen with and without corrosion. The visible cracks were observed to start in different scenarios, and there were distinct differences in load cycles to first observed cracks, which are shown in Table 1. The five non-corroded specimens showed visible cracks at between 2.9 and $3.88 * 10^{5}$ cycles and failed at between 3.79 and $5.02 * 10^{5}$ cycles. The statistical dispersion of visible crack detection and growth damage accumulation is large, which is a typical phenomenon of MSD specimens. The load cycles to visible crack detection of the non-corroded specimens represented $70 \%$ to $80 \%$ of their total fatigue life, and similar behavior was observed in the corroded specimen. The observed reduction due to corrosion in the mean cycles to visible crack detection was $59 \%$ for the specimens corroded to the $5 \%$ to $6 \%$ level.

In non-corroded specimens the crack grew with increasing load cycles from the central holes outward forming a pattern of multi-site damage as shown in Figure 4. Changes in gross failure modes were observed in the corroded specimens with the $5 \%$ to $6 \%$ level. The two dominant failure modes in a corroded specimen are: (i) non-uniform MSD - one crack developed from only one site - at the rivet locations in the upper row and (ii) fatigue cracking at one or more sites in the inner (driven) sheet 5.08 to $7.62 \mathrm{~mm}$ ( 0.2 to $0.3 \mathrm{in})$ below the lower rivet row.
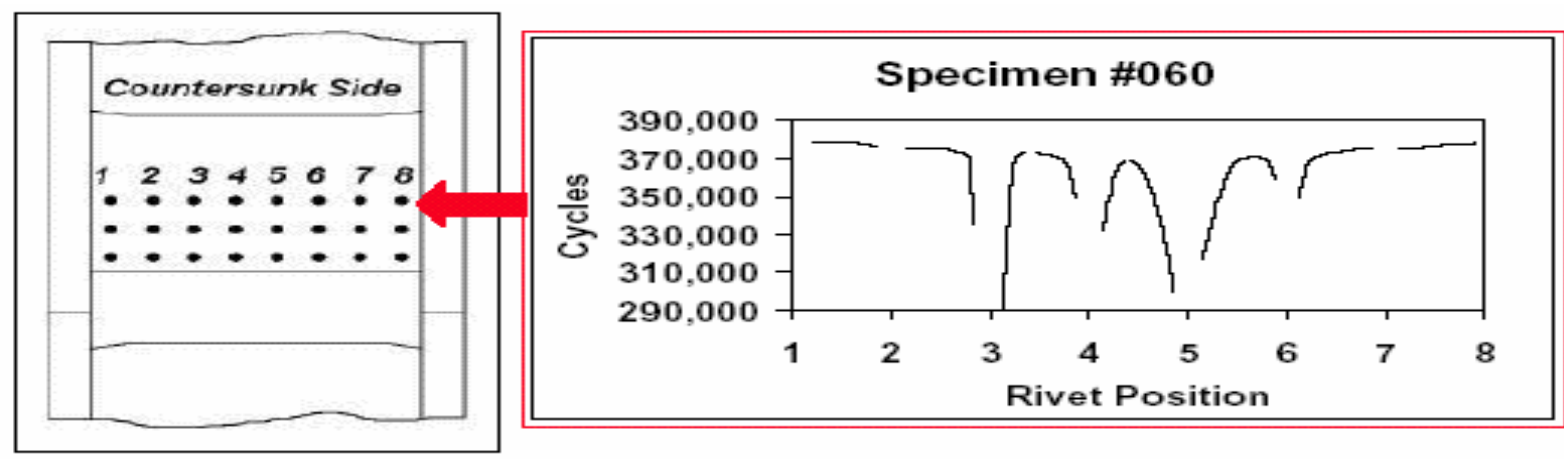

Fig 4. Typical MSD growth pattern in a non-corroded specimen 


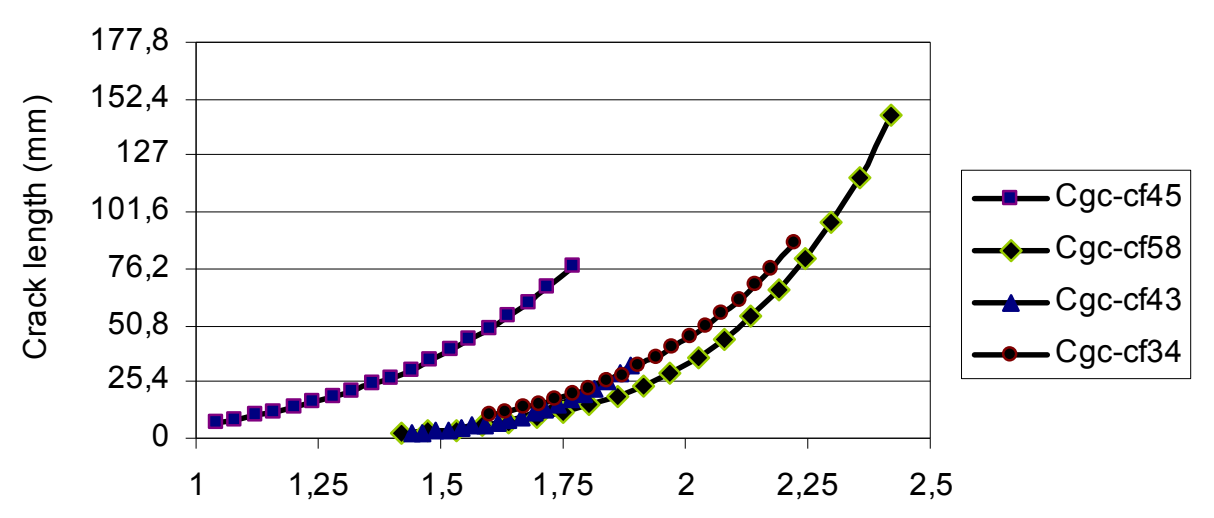

Number of load cycles $\left(x 10^{\wedge} 5\right)$

Fig 5. Crack growth history data of corroded specimens

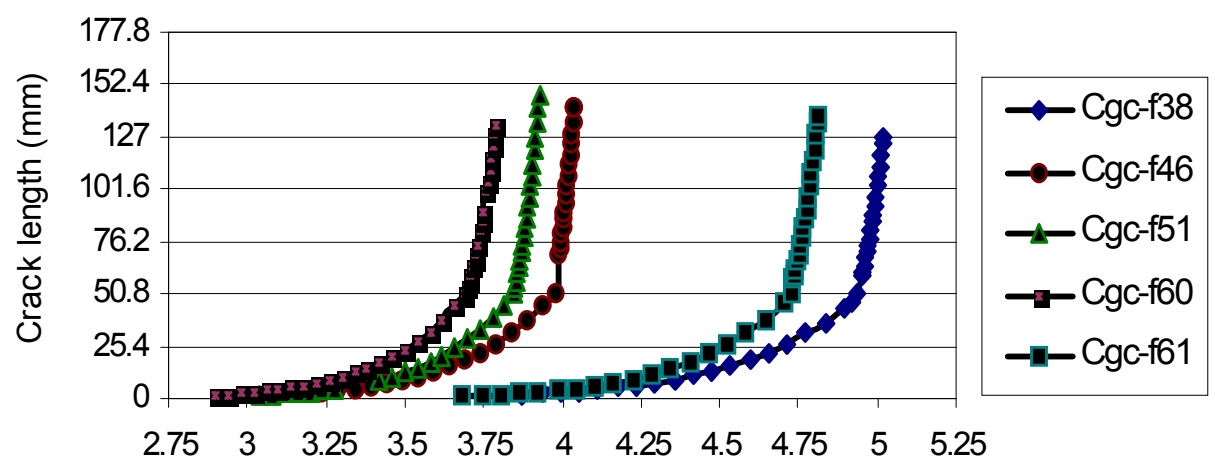

Number of load cycles $\left(\times 10^{\wedge} 5\right)$

Fig 6. Crack growth history data of non-corroded specimens

MSD tends to develop in clusters within the boundaries of a frame-bay. Similarly the linkup of MSD and the formation of a lead crack also tend to occur initially within a frame-bay for this curves that record the sum of all individual crack lengths at any given time. The crack length at a rivet hole is measured from the edge of the drilled hole. For cracks that developed away from the rivet rows, as in some corroded specimens, the aggregate crack length is taken as the total tip to tip crack length. There were several such cracks in a specimen in an interacting MSD formation; overlapping cracks were regarded as linked cracks.

The test data for the crack growth history of the two specimen groups are shown in Figure 5 and 6. In the corroded specimens, the overall crack growth rate was relatively stable during the whole growth period, similar to the growth progression of a single crack. On the other hand, in the non-corroded specimens, first linkup occurred at an aggregate crack length of about $50.8 \mathrm{~mm}$ ( 2 in). Subsequent crack growth was relatively fast and produced a pronounced knee in the growth curve.

With the above observation the total service life of a specimen is divided into two or three stages. For noncorroded specimens, the total fatigue life, $\mathrm{N}_{t}$, is divided into three parts: life to visible cracks or visible damage starting life, $\mathrm{N}_{\mathrm{s}}$, growth life before linkup, $\mathrm{N}_{\mathrm{gl}}$, and growth life after linkup, $\mathrm{N}_{\mathrm{g} 2}$, that follow $\mathrm{N}_{\mathrm{t}}=\mathrm{N}_{\mathrm{s}}+\mathrm{N}_{\mathrm{g} 1}+$
$\mathrm{N}_{\mathrm{g} 2}$. For the corroded specimens to the $5 \%$ to $6 \%$ level, a single stage with growth life $\mathrm{N}_{\mathrm{s}}$, is used for the whole growth period because of their relatively stable growth behavior, and the total fatigue life is $\mathrm{N}_{\mathrm{t}}=\mathrm{N}_{\mathrm{s}}+\mathrm{N}_{\mathrm{g}}$. The visible damage starting life is the number of load cycles at which the first crack was observed, and the total life of a specimen is when the final failure occurred. The growth life is the difference between the total life and the damage starting life $\mathrm{N}_{\mathrm{g}}=\mathrm{N}_{\mathrm{t}}-\mathrm{N}_{\mathrm{s}}$.

In a modern transport aircraft, the critical length of a single longitudinal crack in a fuselage skin is typically in excess of the frame bays about $10.16 \mathrm{~cm}$. Crack growth rates are high when a lead crack reaches a length of several inches. The presence of MSD in adjacent framebays could reduce the critical length of the lead crack. Therefore, first, the splice is considered to have failed when the first linkup occurs at which the length of the aggregate lead crack $a$ reaches a specific value $a_{l k}$. Second, the splice is considered to have failed when the aggregate crack length reaches a critical value $a_{c r}$. The specific crack length for linkup and the critical crack length for final failure is taken from the mean values of the crack length obtained from the test data corresponding to the linkup and failure life, respectively. For a corroded specimen, only the final failure is considered. 


\section{Damage starting life and stochastic growth model}

\subsection{Curve-fitting of test data}

The test data are first imported into MS Excel and then fitted using a growth function, expressed as:

$$
a=C_{1} * N^{C_{2}}
$$

Where $a$ is the aggregate crack length, $\mathbf{N}$ is the number of load cycles, and $\mathbf{C}_{\mathbf{1}}$ and $\mathbf{C}_{\mathbf{2}}$ are two constants taken from the Table 2.

Two separate growth functions are used for the two growth stages of the non-corroded specimens. The junction of the two growth curves is selected to occur where the crack length is $(50.8 \mathrm{~mm}$. The life corresponding to this specific crack length is called the growth rate transition life. The growth rate transition life is close to the linkup life, but the two are not the same. A single function is fitted for the whole growth period of the specimens corroded to the $5 \%$ to $6 \%$ level. The fitted curves are shown in Figure 5 and 6 and the constants determined for the growth functions are listed in Table 2.

The final critical size of the crack $\left(a_{c}\right)$ is taken to be $50.8 \mathrm{~mm}$ for both the corroded and non-corroded specimens. In investigating damage growth behavior, an initial crack is assumed to exist in each specimen. In this work, the length of the initial visible detectable crack $\left(a_{d}\right)$ is taken as $2.032 \mathrm{~mm}$ for all specimens. This is approximately the average crack length for all specimens at the first observation.

Table 2. Constants in fitted growth curves

\begin{tabular}{|c|l|c|c|c|c|}
\hline \multirow{2}{*}{ Specimen \# } & \multicolumn{2}{c|}{ Growth stage 1 } & \multicolumn{2}{c|}{ Growth stage 2} \\
\cline { 3 - 6 } & $\mathrm{C}_{1}$ & $\mathrm{C}_{2}$ & $\mathrm{C}_{1}$ & $\mathrm{C}_{2}$ \\
\hline \multirow{4}{*}{$\begin{array}{c}\text { Non- } \\
\text { corroded }\end{array}$} & Cgc-f38 & $1.39 \mathrm{e}-9$ & 13.18 & $1.90 \mathrm{e}-40$ & 57.69 \\
\cline { 2 - 6 } & Cgc-f46 & $2.16 \mathrm{e}-8$ & 13.29 & $1.21 \mathrm{e}-35$ & 58.84 \\
\cline { 2 - 6 } & Cgc-f51 & $5.59 \mathrm{e}-9$ & 14.62 & $1.97 \mathrm{e}-30$ & 51.30 \\
\cline { 2 - 6 } & Cgc-f60 & $2.48 \mathrm{e}-8$ & 13.93 & $6.60 \mathrm{e}-22$ & 37.86 \\
\cline { 2 - 6 } & Cgc-f61 & $1.70 \mathrm{e}-10$ & 14.92 & $4.52 \mathrm{e}-35$ & 51.40 \\
\hline \multirow{3}{*}{$\begin{array}{c}\text { Corroded } \\
\text { to 5\% - } \\
6 \% \text { level }\end{array}$} & Cgc-cf34 & 0.0194 & 6.48 & & \\
\cline { 2 - 6 } & Cgc-cf43 & 0.0028 & 9.65 & & \\
\cline { 2 - 6 } & Cgc-cf45 & 0.2412 & 4.44 & & \\
\cline { 2 - 6 } & Cgc-cf58 & 0.0057 & 7.82 & & \\
\hline
\end{tabular}

\subsection{Determination of fatigue crack growth function parameters}

Following Yang it is assumed that fatigue crack growth of some items of an airframe is defined by the $12 \mathrm{q}$ formula $[5,4]$ :

$$
a(t)=a(o) /\left(1-\mu(a(o))^{\mu} Q t\right)^{1 / \mu}
$$

Where,

$$
\mu=m / 2-1
$$

In this paper we consider the case when $m \neq 2$.
The parameter $\mu$ - depends on the material characteristics,

$a(0)$ - equivalent beginning size of a crack.

Processing of data for crack growth during fatigue experiments using the least square method, we can get estimates of equation parameters.

Results of processing four fatigue crack growth data for corroded specimens at 5\%-6\% level are given in Table 3.

\begin{tabular}{|c|c|c|c|c|}
\hline $\begin{array}{c}\text { Serial } \\
\text { No. }\end{array}$ & Specimen \# & $\mu$ & $\mathrm{b}_{\mathrm{o}}=\ln \mathrm{Q}$ & $\mathrm{a}(0)$ \\
\hline 1. & Cgc-cf34 & -0.15424 & -9.75393 & $2.37 \mathrm{E}-19$ \\
\hline 2. & Cgc-cf43 & -0.10353 & -9.52048 & $1.48 \mathrm{E}-27$ \\
\hline 3. & Cgc-cf45 & -0.22511 & -9.61464 & $4.51 \mathrm{E}-13$ \\
\hline 4. & Cgc-cf58 & -0.12758 & -9.70537 & $1.63 \mathrm{E}-18$ \\
\hline \multicolumn{2}{|c|}{ Average } & -0.15262 & -9.6486 & $1.13 \mathrm{E}-13$ \\
\hline \multicolumn{2}{|c|}{ Standard Deviation } & 0.052581 & 0.103096 & $2.26 \mathrm{E}-13$ \\
\hline
\end{tabular}

Table 3. Fatigue crack growth parameters for corroded specimens at 5\%-6\% level.

Results of processing of five fatigue crack growth data for non-corroded specimens are given in Table 4.

Table 4. Fatigue crack growth parameters for non-corroded specimens

\begin{tabular}{|c|c|c|c|c|}
\hline $\begin{array}{l}\text { Serial } \\
\text { No. }\end{array}$ & Specimen \# & $\mu$ & $\mathrm{b}_{\mathrm{o}}=\ln \mathrm{Q}$ & $\mathrm{a}(0)$ \\
\hline 1. & Cgc-f38 & 0.432273 & -11.2323 & 0.079004 \\
\hline 2. & Cgc-f46 & 0.44934 & -11.0738 & 0.091935 \\
\hline 3. & Cgc-f51 & 0.334914 & -10.6355 & 0.02707 \\
\hline 4. & Cgc-f60 & 0.249426 & -10.5026 & 0.014186 \\
\hline 5. & Cgc-f61 & 0.322694 & -10.7252 & 0.018577 \\
\hline \multicolumn{2}{|c|}{ Average } & 0.35773 & -10.8339 & 0.046155 \\
\hline \multicolumn{2}{|r|}{ Standard Deviation } & 0.082805 & 0.307091 & 0.036475 \\
\hline
\end{tabular}

\subsection{Simulation of a process of fatigue crack inspection}

It is assumed that some inspection technology is characterized by two values: $a_{d}$ and $w_{i} ; a_{d}$ is the minimum size of a detectable crack and $w$ is interpreted as probability that the earlier scheduled inspection will be made with required accuracy. Service time when crack becomes detectable $\mathrm{t}_{\mathrm{d}}$ and service time to fatigue failure $t_{f}$ are defined below:

$$
t_{d}=\frac{C_{d}}{Q} \quad t_{f}=\frac{C_{f}}{Q}
$$

We consider that $t_{d}$ and $t_{f}$ are functions of random variable $Q$, where $C_{d}$ is a constant for both non-corroded and corroded specimens with different $a(0)$, i.e

$$
C_{d}=\frac{1-\left(\frac{a(o)}{a_{d}}\right)^{\mu}}{\mu(a(o))^{\mu}}
$$

$a_{d}$ is a an initial detectable size of the fatigue crack 
$C_{f}$ is a constant for the case when $\mu$ - negative. It takes place for the corroded specimens

$$
C_{f}=\left[\frac{\left(\left(K_{c} / \sigma_{\max }\right)^{2} * 1 / \pi\right)^{\gamma}-(a(o))^{\gamma}}{\gamma}\right]
$$

$C_{f}$ is a constant for the case when $\mu$ - positive. It takes place for the non-corroded specimens.

$$
C_{f}=\frac{1-\left(\frac{a(o)}{\frac{K_{c}{ }^{2}}{\sigma_{\max }{ }^{2} \pi}}\right)^{\mu}}{\mu a(o)^{\mu}}
$$

Bar chart of crack undetectable and crack detectable time periods (CUCDTP) in both cases are shown in Figure 7 and 8 .

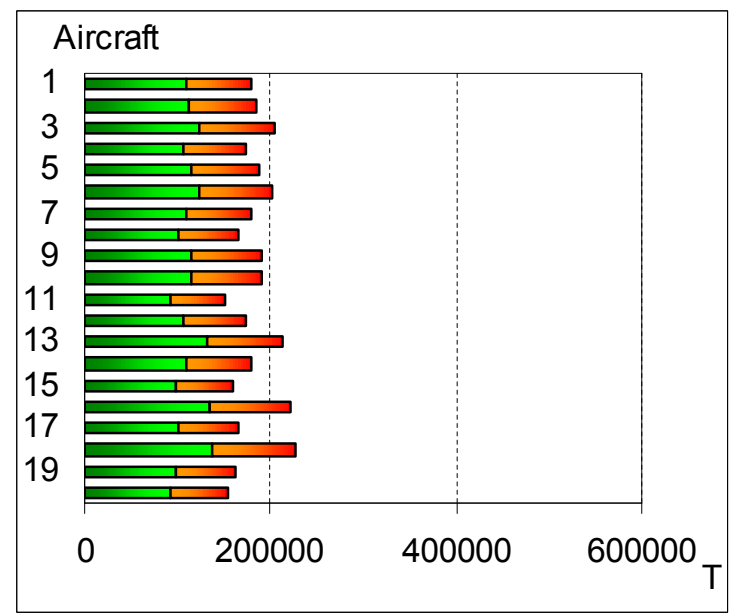

Fig 7. Bar chart of CUCDTP for the corroded specimens at $5 \%$ and $6 \%$ level

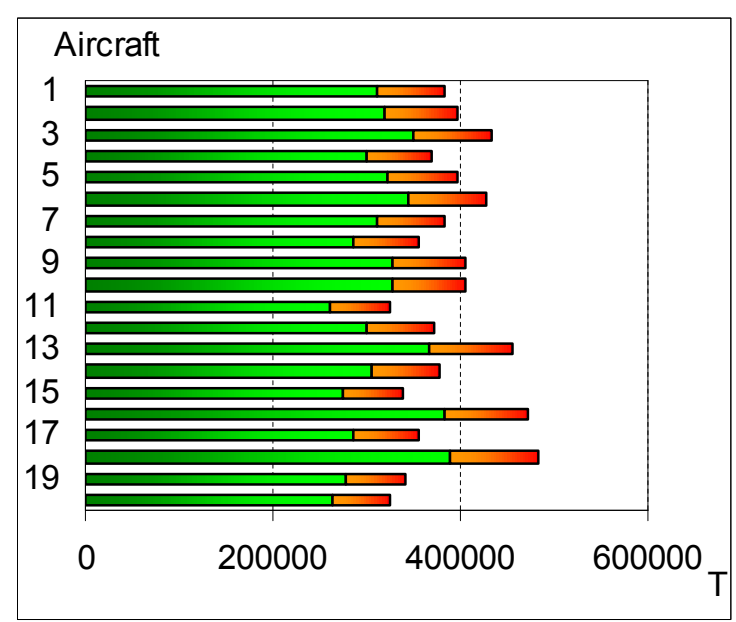

Fig 8. Bar chart of CUCDTP for the non-corroded specimens

\subsection{Estimation of fatigue failure probability}

If we use the Monte Carlo (MC) method then the failure probability in the interval $\left(t_{d}, t_{f}\right)_{j}$ with $r_{j}$ inspections on the $j$-th airplane is defined by formula:

$$
\hat{p}_{f 1 j}=(1-w)^{r_{j}}
$$

where $w$ is a probability that planned inspection will be made with required accuracy

Then for $\mathrm{N}$ airplanes (or for $\mathrm{N}$ Monte Carlo trials) mean failure probability $\left(P_{f}\right)$ will equal:

$$
\hat{p}_{f}=\frac{1}{N} \sum_{j=1}^{N} P_{f 1 j}
$$

For the case when $w=1$, it can be shown that $[1,2]$ :

$$
p_{f}=\sum_{i=1}^{n} p_{i}^{\bullet}
$$

where

$$
\begin{gathered}
p_{i}^{*}=\left\{\begin{array}{l}
0, \text { if } \frac{C_{d}}{t_{i-1}} \leq \frac{C_{f}}{t_{i}} \\
\pi_{i}, \text { if } \frac{C_{d}}{t_{i-1}}>\frac{C_{f}}{t_{i}}
\end{array}\right. \\
\pi_{i}=F_{Q}\left(\frac{C_{d}}{t_{i-1}}\right)-F_{Q} \frac{C_{f}}{t_{i}}= \\
\pi_{i}=\phi\left(\frac{\ln \left(C_{d} / t_{i-1}\right)-\theta_{0}}{\theta_{1}}\right)-\phi\left(\frac{\ln \left(C_{f} / t_{i}\right)-\theta_{0}}{\theta_{1}}\right)
\end{gathered}
$$

\subsection{The choice of first interval $t_{1}$}

The choice of first interval $t_{1}$ can be made on the condition of limitation of probability of failure in interval $\left[0, t_{1}\right]$ by small value $\varepsilon$ :

$$
t_{1}: P\left(\ln T_{f}<\ln t_{1}\right)=\varepsilon=0.001
$$

Usually it is assumed that $\ln T_{f}$ has normal distribution $\mathrm{N}\left(\theta_{0}, \theta_{1}^{2}\right)$ where $\theta_{0}=\theta_{0}\left(\ln T_{f}\right), \theta_{1}=\theta_{1}\left(\ln \mathrm{T}_{\mathrm{f}}\right)$ are mean and standard deviation of $\ln T_{f}$ i.e.

$$
T_{f}=\frac{C_{f}}{Q}
$$

Then

$$
\begin{aligned}
& P\left(\ln T_{f}<\ln t_{1}\right)=\Phi\left[\frac{\ln t_{1}-\theta_{0}\left(\ln T_{f}\right)}{\theta_{1}\left(\ln T_{f}\right)}\right] \\
& \ln t_{1}=\Phi^{-1}(\varepsilon) * \theta_{1}\left(\ln T_{f}\right)+\theta_{0}\left(\ln T_{f}\right)
\end{aligned}
$$


Coming from the relationship.

$$
\ln T_{f}=\ln C_{f}-\ln Q
$$

One can obtain

$$
\ln t_{1}=\ln C_{f}-\theta_{0}(\ln Q)+\Phi^{-1}(\varepsilon) * \theta_{1}\left(\ln T_{f}\right)
$$

If all the other $\Delta_{\mathrm{i}}$ are equal, then interval between inspections is as follows:

$$
\Delta=\frac{\left(T_{S L}-t_{1}\right)}{n}
$$

Where $t_{S L}$ is the specified life of an aircraft and $n$ is number of inspections (including first interval).

Examples of calculation of $t_{l}$ for the corroded specimens are given in the Table 5.

Table 5. First time interval $t_{1}$

\begin{tabular}{|c|c|c|c|c|}
\hline$\varepsilon$ & $\Phi^{-1}(\varepsilon)$ & $\operatorname{lnCf}$ & $\operatorname{lnt}_{1}$ & $\mathrm{t} 1=\exp (\operatorname{lnt} 1)$ \\
\hline 0,001 & $-3,09024472$ & 2,4734724 & 11,65854 & 115674,9109 \\
\hline
\end{tabular}

Examples of calculation of $t_{1}$ for the non-corroded specimens are given in the Table 6.

Table 6. First time interval $t_{1}$

\begin{tabular}{|c|c|c|c|c|}
\hline$\varepsilon$ & $\Phi^{-1}(\varepsilon)$ & $\operatorname{lnCf}$ & $\operatorname{lnt}_{1}$ & $\mathrm{t} 1=\exp (\operatorname{lnt} 1)$ \\
\hline 0,001 & $-3,09024472$ & 2,0431005 & 12,41344 & 246085,9357 \\
\hline
\end{tabular}

All the other moments of inspection are defined by the following formula:

$$
t_{i}=t_{1}+\Delta(i-1)
$$

Where $i=(1,2,3 \ldots \mathrm{n})$ and 10

Relevant curves $\mathrm{P}_{\mathrm{f}}=\mathrm{P}_{\mathrm{f}}(\Delta)$ are shown in Figure 9

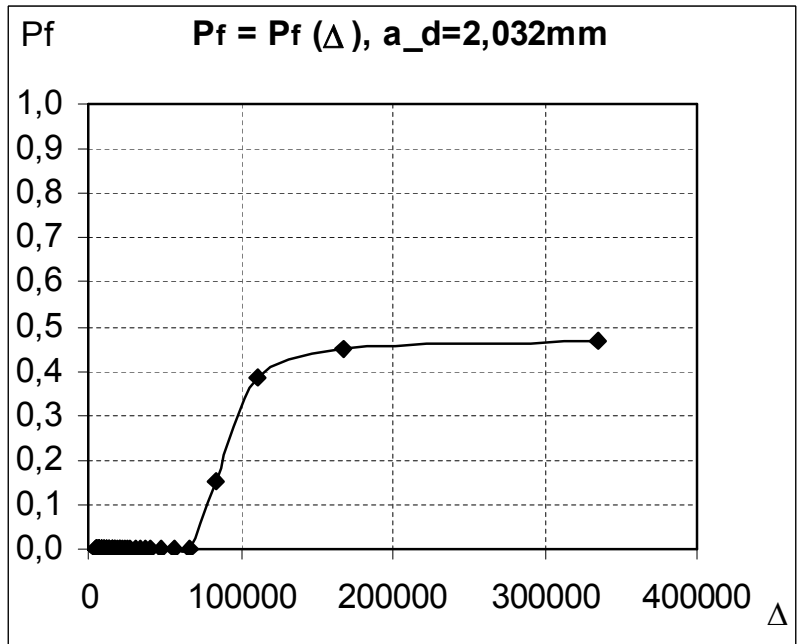

Fig 9. Failure probability for the corroded speciemn with specified life $=450000$ cycles

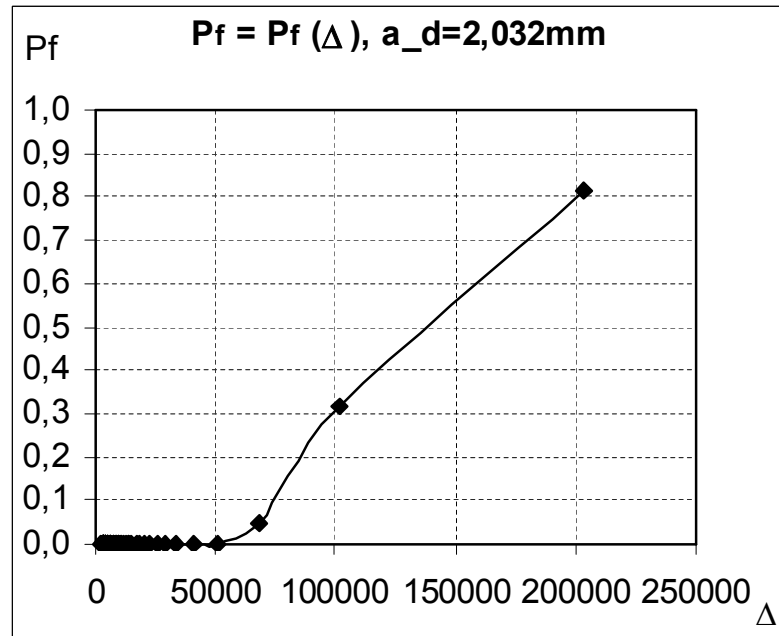

Fig 10. Failure probability for the non-corroded speciemn with specified life $=450000$ cycles

At first glance, it is surprising that for the corroded specimens the probability of failure does not grow higher than 0.48 . The reason for that is that at the first inspection $\left(\mathrm{t}_{1}=115674\right)$ we discover approximately $52 \%$ of cracks (Figure 9). But for the non-corroded specimens (at $t_{1}=$ 246085) we do not see any fatigue crack (Figure 10). This means that a more sophisticated strategy of $t_{1}$ choice should be developed. But this is a subject for another paper.

\subsection{Choice of the number of inspections}

We can choose $\mathrm{n}$ (number of inspections) for allowable failure probability $(\mathrm{Pf} \approx 0.017)$. The value 0.017 should be considered just as an example (Really it is defined by the limited time of Monte Carlo analysis).

Monte Carlo method is being used when inspection is carried out at $\mathrm{tl}>\mathrm{td}$. Detectable size of the crack is $2.032 \mathrm{~mm}$; failure size of the crack is $50.8 \mathrm{~mm}$.

The required numbers of inspections (n) for different specified lives (SL), which are expressed in cycles, are shown in Table 7 and 8 for corroded and non-corroded specimens respectively.

To remind that the first interval t1 $(\varepsilon)=$ 115674,9109 cycles (Table 5).

Table 7. Required number of inspections for corroded specimens

\begin{tabular}{|c|c|c|}
\hline \multirow{2}{*}{ Specified Life } & $\mathrm{w}=1$ & $\mathrm{w}=0.9$ \\
\cline { 2 - 3 } & $\mathrm{n}$ & $\mathrm{n}$ \\
\hline 400000 & 4 & 8 \\
\hline 450000 & 5 & 9 \\
\hline 500000 & 6 & 11 \\
\hline
\end{tabular}

To remind that the first interval t1 $(\varepsilon)=$ 246085,9352 cycles (Table 6). 
Table 8. Required number of inspections for non - corroded specimens

\begin{tabular}{|c|c|c|}
\hline \multirow{2}{*}{ Specified Life } & $\mathrm{w}=1$ & $\mathrm{w}=0,9$ \\
\cline { 2 - 3 } & $\mathrm{n}$ & $\mathrm{n}$ \\
\hline 400000 & 3 & 4 \\
\hline 450000 & 4 & 6 \\
\hline 500000 & 5 & 7 \\
\hline
\end{tabular}

Where $w$ is a probability that planned inspection will be made with required accuracy.

\section{Conclusions}

For corroded specimens, the required number of inspections $(n)$ (for reliability $R=1-0.017$ ) increases. When $\mathrm{T}_{\mathrm{SL}}=400000$ cycles, it is less significant for the case when $\mathrm{w}=1$ where the required number of inspections increases from 3 to 4 . But it is very significant for the case when $\mathrm{w}=0.9$ where the number of inspections increases from 4 to 8 , i.e. that is two times higher. This shows that with the influence of corrosion the number of required inspections doubles in the case of corroded specimens compared to non-corroded specimens.

\section{References}

1. Paramonov Yu.M., Bharati R. Mathematical models of the process of airframe fatigue problem solution for the purpose of automated system development //
Transactions of RAU, Mechanical Department. 1997. - P. 123-126.

2. Wahab M.S., Paramonov Yu.M. Influence of corrosion on the required number of an airframe inspection // Proceedings of the International Conference "Reliability and Statistics in Transportation and Communication (RelStat'03) 1617 October 2003. - Riga: Transport and Telecommunication Institute, 2004. - Vol 5, No 1. P. 180-190.

3. Xiong Y., Eastaugh G., Shi G. Probabilistic failure analysis of fuselage splice joints with multiple site fatigue damage and corrosion // Structural Integrity for the next Millennium. Proceedings of the Twentieth ICAF (International Committee on Aeronautical Fatigue) Symposium, Bellevue, Washington, USA, 14-16 July 1999/ Edited by Bader R.M., Rudd J.L. 1999. - 2 Volumes. - 1232 p.

4. Yang J.N. Statistical crack growth in durability and damage tolerant analysis // $22^{\text {nd }}$ Structures, Structural Dynamics and Materials Conference. - 1980. - P. 3849.

5. Парамонов Ю.М., Кузнецов В.П. Живучесть авиационных конструкций. Оценка эффективности эксплуатации по состоянию МУ. По выполнению самостоятельной роботы. - 1990. - 24 с. 